\title{
Discussion on Ideological and Political Management Level of College Students
}

\author{
Shengnan Liu
}

\author{
Student Department, Liaoning Jidian Polytechnic, Dandong,118009, China
}

Keywords: ideology and politics of college students; management level; improvement approach

\begin{abstract}
Ideological and political level of college students is closely associated with education development in each period. Ideological and political of colleges should also be valued. According to current situations, proper management of ideology and politics represents such defects of laggard cognition, imperfect system and unmatched system. Ideological and political accomplishment of college students should improve. This requires management improvement. So, this paper proposes improvement approaches of ideological and political management and provides useful reference for future management work.
\end{abstract}

\section{Introduction}

The increase in social transformation speed and international situation also highlight variable general trend. Under such situation, college students are faced with new difficulties of ideology. Ideological and political management fails to change old cognition. The cognition under uniform architecture is lost. Multi-level communication is neglected. To solve the above problems, current management state should be clearly identified so that students can clearly know fundamental guidance and conscientiously constrain daily behaviors. It is required to focus on discovering ideological defects, and preset diversified ideological and political activities to make students own due accomplishment and level.

\section{Identity current situation}

Ideological and political work in colleges gains prominent effects. The survey report shows that college students can recognize and check various problems in current period through rational analysis. However, as the situation changes, internationalization trend stands out in colleges. Multimedia under novel science and technology architecture is also continuously accepted. Ideological and political management is facing multi-level new problems. Thus, it is required to identity management orientation under macroscopic situation and improve original identification ability as well as ideological and political level. To be more specific, management background under new situation reflects the following characteristics:

(I) New difficulties in transition period

Total trend in the transition period increases peculiar difficulties to ideology and politics of colleges. In the face of potential progress opportunity, multiple characteristic contradictions are prominent for existing economic society. Social interest relationship has complex trend. Benefits pattern under multi-variant architecture is being changed gradually. The objects involved interests are diversified and the architecture also has complex characteristics. Benefits are related to bad emotion. Common psychological difficulties of college students also gradually increase. Colleges are included in a part of social architecture. These potential contradictions will reflect value orientation and behavioral characteristics of college students. Diversification under social architecture will bring many confusions and challenge original thinking framework.

The subjects of ideological and political management should check students' dynamics anytime. In case of nay bad mood, they should coordinate and counsel in time, guide students to continuously regulate themselves towards preset positive mentality.

(II) Work trend under international situation

Higher education development under internationalization trend gives rise to potential difficulties. 
As integrated architecture course deepens, colleges should create cultivation objectives in new period and adapt ever-changing international trend. In recent years, special international communication of college students highlight frequent progressive increase trend. Overseas study and relevant visit course are also expanded continuously. For example, in last year, the number of students studying abroad exceeded 2.6 million and the number of those returning to China after overseas study exceeded 0.9 million.

Overseas study exchange under the situation of frequent academic communication and popularity promotes preset teaching progress of colleges. Meanwhile, information expansion accepted by students and selection range enlarge. Students reflect diversified thinking and personality, and impact department culture and values in core architecture. This increases complexity to daily ideological and political guidance.

(III) Ever-changing media

Multiple media under new science and technology synergy highlight total trend. Fission development of network technique represents living normality. College students get used to contacting network. More than $90 \%$ college students regard network communication channel as an exchange bridge. Microblog, WeChat, forum and associated blog break through communication mode in traditional architecture.

Under such situation, network integrates information communication and release properties, public opinion delivery properties, mobilization and peculiar aggregation property. It is regarded as an important channel of communication. Network replaces original social architecture. Irrational and characteristic cognition within right and wrong category coincides mutually, affects multiple public opinions, daily life and value orientation accepted by students. It is difficult to face alternate network public opinions and avoid potential harmful interference.

\section{Existing defects}

(I) Failure to accept new cognition

Total idea of ideological and political management represents reason hierarchy. Idea guidance under such intangible situation generates prominent multiple effects on behaviors between teachers and students and also involves management effect hierarchy. Such cognition accepted by colleges usually tends to control and regulation, with compulsive constraint. Such old cognition neglects self-progress of deep layer.

Preset management path should be equal to usual service process. According to original policy guidance, corresponding regulations are constructed. This creates the optimum condition for follow-up ideological and political education and also provides stable guarantee in each period. Alternated complex situation should correspond to novel cognition. It is required to change old cognition, create multi-directional thinking path under open architecture. In usual practice, it is required to continuously promote improvement of management level.

(II) Potential mechanism loophole

Management mechanism preset for ideological and political management highlights simplification defect. In accordance with document guidance, this work should be uniformly arranged and deployed by Party committees of each department. The principal is responsible for usual management. Administrative system in each hierarchical framework should be set to implementation subjects of details. Existing management path is still deployed by the Party committee in inform architecture. The Party committee controls ideological and political education under comprehensive situation.

The Party committee and associated administrative system fail to alternate such role orderly. The roles are ambiguous. The system fails to specify the advantages and promote enthusiasm of this category. Responsibility departments in colleges and departments fail to create regulations and systems complying with characteristics. The functions about ideological and political management are not clear. Working efficiency is low. Departments highlight responsibility cross and disputes which threaten daily management. To solve the above difficulties, it is required to well solve several potential loopholes of mechanism and prudently avoid them. 
(III) Internal characteristic correlation deficiency

The total system preset for ideological and political management covers multiple levels: education within college and department category, cognition guidance under social architecture and daily family education. The system with comprehensive characteristics should be able to facilitate communication and do usual management well. In existing cognition, many parties are deficient and fail to properly communicate.

In current age with rapid Information update speed, students accept multiple public opinions. Thinking cognition of college students fails to become mature. If usual guidance is not focused on and unhealthy trend exists, students will be affected. Colleges fail to support practice opportunities. Thus, present education process derail from society under general situation.

Usual behavior paths of family members are influenced by potential characteristics. Families should cooperate with colleges and departments to jointly promote improvement of ideological and political level. Due to regional constraint of objective characteristics, families weaken original guidance function and fail to connect with education present by colleges. The responsible organizations of ideological and political education are set to administrative Party committee of colleges. Due to the lack of adjustment and communication, college departments with scientific research nature fail to participate in ideological and political education.

\section{Level improvement paths}

(I) Original ideological and political orientation

Overall cognition under science architecture should be confirmed. Original thought and cognition decide daily behaviors. If ideological and political management of colleges in this category fails to replace such cognition anytime, management loopholes in each period will be caused. It is required to follow people first, enhance service cognition in ideological and political category, respect all students and make them conscientiously accept management.

Individual differences used to identity detail characteristics should be noticed. Novel management under differentiation architecture should be preset. After prudent guidance, due subject position of college students should be highlighted. It is required to mobilize potential enthusiasm and make students consciously fuse in this architecture through daily practice, accept flexible novel ideas, continuously boost response speed and prudently encounter alternate novel situations. Multiple measures present should have flexible features.

For example, ideological and political management of a college including annual report accept novel technology under 3D architecture so that students create situational play and interesting micro-film through autonomous exploration. This 3D and vivid novel mode highlights classical image. Publicity pictures can be preset for classical figures. Besides, DV fragments are produced in this category. These fragments can be uploaded campus microblog and associated Renren. In addition, present report fragments are also added on the network platform that students use. Through such new path, advanced science and technology patch promotes extension and delivery of ideological and political cognition.

(II) Create novel mechanism

Perfecting regulations and mechanism under the architecture can promote management level improvement. Old mechanism hinders progress of this category. It is required to identity unique features of colleges and confirm construction policy under macroscopic situation. These features include regional unique features and subject features created by colleges. The overall framework on which mechanism implementation is based should be implemented prudently. Mechanism system under systematism architecture integrates Party committee and multi-level administration in colleges. Student union and organizations constructed by associated Youth League Committee and class should be able to drive usual work progress.

For example, a counselor in a college creates flexible activity forms to attract students. Aiming at different grades, famous teacher library is set up under corresponding architecture. Annual activity frequency tallies with students' preferences. Novel modes include usual video analysis, interview and interactions in colleges. Preset contents highlight unique wonderful features. 
Ideological and political work present real effects and is closely related to students' acceptance degree. All students should really accept this guidance. Management connotation should approach usual daily life and add original pertinence. For instance, counselors should check and identify potential thought confusion and explain problems for students in their spare time in dormitories and special activity occasions, really care for students and help them solve multi-level life problems. Only in this way, peculiar attraction of ideology and politics can increase to promote effect improvement.

(III) Promote communication

Under general trend of fierce competitions, colleges should cooperate with students, families and multiple forces under social architecture to seek the optimal mechanism. Thus, it is required to well coordinate different members in the system and promote communications. Preset educational mechanism should create internal consensus and identity basic target in overall architecture. It is required to cooperate with all students to discover potential self-advantages and recognize original core value.

Not just should fundamental value guidance be specified, but also interesting activities should be created. Through gradual penetration, students should discover their shortcomings and fuse in the set activities. Novel information should have timeliness feature and stimulate cognition interest. Regular publicity activities should be adopted.

For example, classical examples should be selected so that students are easy to accept. Encouragement stories about the growth of party members should be present in each grade, and unique feelings should be shared. The optimal models can be selected through evaluation. Story-telling session and advanced deed praise can be conducted regularly. In this way, outstanding models can stimulate students' potential driving force.

\section{Conclusions}

Under fierce competitions, college ideology and politics have many problems. Ideological and political management work has system feature under complex architecture. It is required to recognize effect of daily management, make students consciously accept new knowledge and extend original horizon. Origin theory should be used in usual practice. In the face new difficulties in each period, it is required to promote gradual improvement of management level.

\section{References}

[1] Feng Gang, Learning and implementing spirit of the $18^{\text {th }}$ congress of the communist party of China and striving to improve quality of ideological and political education of college students [J]. Journal of Ideological \& Theoretical Education, 2013 (02)

[2] Wang Yinlan, “Trilogy” of improving ideological and political quality of college students exploration of ideological and political education path for college students [J]. Journal of Xinzhou Teachers University, 2014 (01)

[3] Zheng Yongting, Theoretical research on improving ideological and political quality of college students [J]. Studies In Ideological Education, 2013 (06)

[4] Zhang Sheqiang, Improvement of science level of ideological and political education of college students guided by scientific development perspective [J]. Academic Forum, 2013 (04)

[5] Zhao Yetian, The key point of improving ideological and political quality lies in socialist core value system education [J]. Journal of Ideological \& Theoretical Education, 2010 (07) 